\title{
Application of the Taylor Equation to Five-Power-Law Creep Considering the Influence of Solutes
}

\author{
Michael E. Kassner \\ Chemical Engineering and Materials Science, University of Southern California, 3650 McClintock Ave, \\ Los Angeles, CA 90089, USA; kassner@usc.edu
}

Received: 18 September 2018; Accepted: 8 October 2018; Published: 11 October 2018

\begin{abstract}
This study determines the feasibility of describing the flow stress within the five-power-law creep regime, using a linear superposition of a dislocation hardening term and a significant solute strengthening term. It is assumed that the solutes are randomly distributed. It was found that by using an energy balance approach, the flow stress at high temperatures can be well-described by the classic Taylor equation with a solute strengthening term, $\tau_{0}$, that is added to the $\alpha \mathrm{MGb} \rho^{1 / 2}$ dislocation hardening term.
\end{abstract}

Keywords: creep; microstructural features; constitutive equations

\section{Introduction}

This paper addresses the theoretical validity of the application of a Taylor equation to five-power-law creep in pure alloys and class $\mathrm{M}$ alloys. Previous work on aluminum and stainless steel by the author [1-3] shows that the density of dislocations within the subgrain interior influences the flow stress for steady-state substructures as well as primary creep. The hardening is consistent with the Taylor relation if a linear superposition of solute hardening $\left(\tau_{0}\right.$, or the stress necessary to cause dislocation motion in the absence of a dislocation substructure) and dislocation hardening $\left(\cong \alpha \mathrm{MGb} \rho^{1 / 2}\right)$ is assumed, or

$$
\tau=\tau_{\mathrm{o}}+\alpha \mathrm{MGb} \rho^{1 / 2}
$$

It appears that dislocation hardening is athermal and the constant, $\alpha$, is temperature independent. The value of $\alpha$ is consistent with the range of values observed in cases where dislocation hardening is unambiguous. $\mathrm{M}$ is the Taylor factor, $\mathrm{G}$ is the shear modulus, $\rho$ is the Frank network dislocation density, $\mathrm{b}$ is the Burgers vector and $\tau$ is the applied stress. Part of the reason that the question of superposition is important is because, historically, the $\tau_{\mathrm{o}}$ term is not included or is very small. The question is whether for cases where the $\tau_{\mathrm{o}}$ term is large, a linear superposition in fundamentally reasonable. This endeavor complements the earlier work by the author that demonstrated, that, at least phenomenologically, the superposition (i.e., Equation (1)) is effective.

It must be mentioned that the basis for strengthening in five power-law -creep in generally attributed to the Frank dislocation network such as [4-7]. Others have held to the proposition that subgrain walls are associated with the strength of materials within the five-power-law regime $[8,9]$. This Communication considers the Frank network to be associated with strength and the rate-controlling process for creep.

References [1,2] show for the case of annealed (very low dislocation density) $99.999 \%$ pure aluminum, that the yield stress appears to be a significant fraction of the, eventual, steady-state flow stress. This is illustrated in Figure 1. This is also true for 304 stainless steel, a class M (pure metal behavior) alloy. It is assumed that there are no long range internal stresses as consistent with the findings of $[10,11]$. In both cases the yield stress of the annealed metal is roughly 0.5 at $371{ }^{\circ} \mathrm{C}$ for $\mathrm{Al}$ 
and 0.3 at $750{ }^{\circ} \mathrm{C}$ for 304 stainless steel of the steady-state flow stress. Clearly, a description of the stress at steady-state must consider both the solute and the dislocation features of the microstructure. In the author's case, the dislocation feature has been suggested to be the Frank dislocation network within the grain and subgrains of the polycrystalline aggregate. Careful work by the author and coworkers determined that the Frank network of dislocations, rather than the subgrains, is the dislocation feature associated with elevated temperature strength $[1,2,6]$.

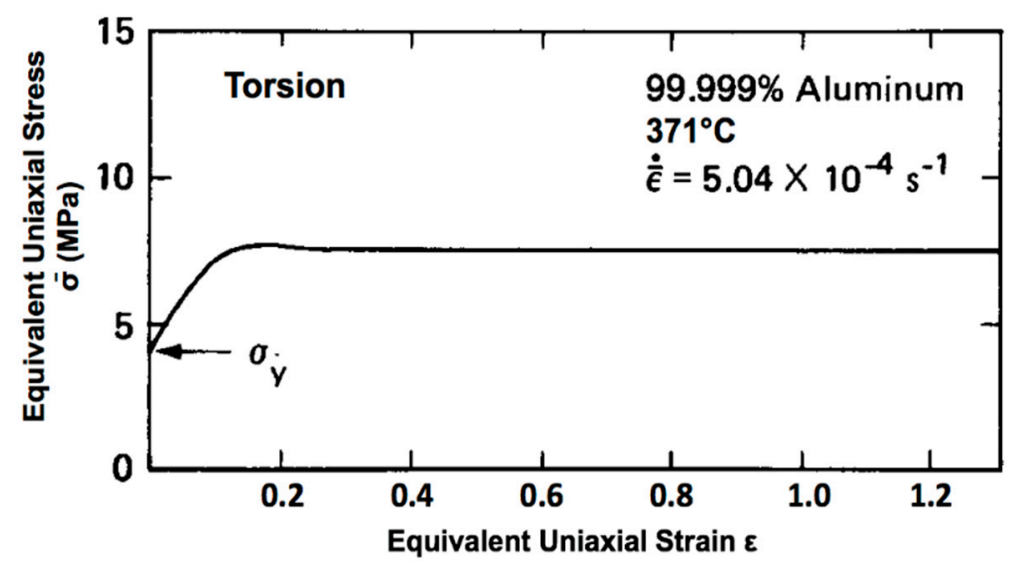

Figure 1. The stress versus strain behavior of $99.999 \%$ pure polycrystalline aluminum at $371{ }^{\circ} \mathrm{C}$ in torsion.

The yield strength in Figure 1 can only be attributed to the small amount of solute. The grain size of the aluminum in the figure is about $0.5 \mathrm{~mm}$. There are a variety of possibilities to superimpose the strengthening variables (e.g., linear summation, root mean square as in [6], one hardening term exclusively controls the strength, etc.). The current work explores a simple linear superposition such as in Equation (1) that appears phenomenologically effective. The possibility that part of the annealed yield strength could be a lattice friction stress (similar to a Peierls stress) should be acknowledged.

\section{Analysis and Discussion}

The solutes in the present case are considered to be randomly dispersed. The Frank network coarsens with time at temperature and the link lengths increase. Eventually, some of the links are sufficient in length to operate a multiplication mechanism (e.g., Frank-Read source) and plasticity (creep) ensues. This multiplication also causes network refinement. Thus, there is both recovery (network coarsening) and hardening (network refinement) and steady-state is a balance of these two processes. The yield stress of the starting annealed material would be very low in the absence of the solute as the network strength is presumed to be very low [5]. At the yield stress, then, plastic flow is dictated by the impurities. At 99.999 (wt)\% purity, roughly 10 ppm of impurities are present or roughly one in $10^{5}$ host (solvent) atom sites are occupied by impurities. This suggests that the separation between impurities is roughly 50 atomic diameters or $13 \mathrm{~nm}$. This separation is assumed constant with dislocation hardening. Hardening by solutes might occur by elastic interaction between the solute and the dislocations. From the bowing equation,

$$
\tau=\mathrm{Gb} / \mathrm{r}
$$

If each solute atom perfectly pins a dislocation then the yield strength is roughly $G / 25$, which is much too large. The dislocation must "tear away' from the solute at a much lower stress. The solute atoms do not diffuse to "follow" the dislocation as with three-power-law creep [3]. There are a large variety of solutes that comprise the $0.001 \%$ total impurity concentration.

Once the stress has reached the yield stress, dislocation bowing can occur within the Frank network. As the dislocation bows it must (1.) perform work to tear away from the solute atoms that 
elastically interact with the stress fields of the dislocation and (2.) also perform work to compensate for the increase in elastic strain energy associated with increasing dislocation line length with bowing. Defining:

- 1 = bowed dislocation length;

- $1_{\mathrm{s}}=$ distance between solutes;

- $\mathrm{r}=$ radius of bowed dislocation links;

- $\Delta \mathrm{V}=$ difference in volume between solute and solvent;

- $\quad \mathrm{P}=$ hydrostatic pressure component of the dislocation stress field;

- $\mathrm{k}=$ constant;

- $\theta=$ radians

Then, if the loop expands by dr, by the First Law,

$$
(\tau \mathrm{bl}) \mathrm{dr}=\theta \mathrm{dr}\left[\mathrm{Gb}^{2} / 2\right]+\mathrm{dr}\{\mathrm{d}(\mathrm{P} \Delta \mathrm{V}) / \mathrm{dr}\}\left(/ 1 / 1_{\mathrm{s}}\right)
$$

Again, this is just that the work done by the applied stress as the dislocation moves, is equal to the increase in elastic strain energy of dislocation line plus the work done to "tear away" the dislocation from the solutes. Equation (3) leads to,

$$
\begin{aligned}
\tau \mathrm{bl} & =1 / \mathrm{r}\left[\mathrm{Gb}^{2} / 2\right]+\left(1 / 1_{\mathrm{s}}\right)\{\mathrm{d}(\mathrm{P} \Delta \mathrm{V}) / \mathrm{dr}\} \\
\tau & =[\mathrm{Gb} / 2 \mathrm{r}]+[\mathrm{d}(\mathrm{P} \Delta \mathrm{V}) / \mathrm{dr})] /\left(\mathrm{bl}_{\mathrm{S}}\right)
\end{aligned}
$$

for a typical $r$, and a simple arrangement of dislocations,

$$
\begin{gathered}
\mathrm{r}=\mathrm{kl}=\mathrm{k} / \rho^{0.5} \\
\left.\tau=\left[\mathrm{Gb} \rho^{0.5}\right] / 2 \mathrm{k}+[\mathrm{dP} \Delta \mathrm{V}) / \mathrm{dr}\right] /\left(\mathrm{bl}_{\mathrm{s}}\right)
\end{gathered}
$$

In the above, tau is the resolved shear stress on the loop. Therefore, for the applied stress or,

$$
\tau_{\mathrm{a}}=\tau_{\mathrm{o}}+\alpha \mathrm{MGb} \rho^{1 / 2}
$$

or Equation (1), which is the classic Taylor equation, with, in this case, a $\tau_{\mathrm{o}}$ that is a significant fraction of the flow stress. Thus, this article fundamentally confirms that dislocation hardening within the fivepower-law creep regime, can be described by a classic Taylor equation using a linear superposition of a dislocation hardening term and a solute strengthening term. Because $\tau_{\mathrm{o}}$ is a thermally activated term and $\alpha \mathrm{MGb} \rho^{1 / 2}$ is the athermal term, then the constant $\alpha$ is expected to be of a similar value that those cases where dislocation hardening is unambiguous. In the authors earlier work on dislocation hardening in five-power-law creep [1-3], the $\alpha$ value is reasonable for dislocation hardening.

\section{Conclusions}

This study determined the theoretical feasibility of describing dislocation hardening within the five-power-law creep regime using a classic Taylor equation using a linear superposition of a dislocation hardening term and a solute strengthening term. It was assumed that the solutes are randomly distributed. This assumption and an energy balance approach demonstrated that the high temperature flow stress can be described by the classic Taylor equation with a linearly added solute strengthening term to the dislocation hardening term. The fundamental analysis complements earlier work that showed that the flow stress at steady-state can be satisfactorily described by a summation of a dislocation hardening terms consistent with the Taylor equation and a solute strengthening term. 
Acknowledgments: The support by the National Science Foundation under grant DMR-1401194 is greatly appreciated.

Conflicts of Interest: The authors declare no conflict of interest.

\section{References}

1. Kassner, M.E. Taylor Hardening in Five Power Law Creep of Metals and Class M Alloys. Acta Mater. 2004, 52, 1-9. [CrossRef]

2. Kassner, M.E. A Case for Taylor Hardening During Primary and Steady-State Creep in Aluminum and Type 304 Stainless Steel. J. Mater. Sci. 1990, 25, 1997-2003. [CrossRef]

3. Kassner, M.E. Fundamentals of Creep in Metals and Alloys, 3rd ed.; Elsevier: Amsterdam, The Netherlands, 2015; pp. 1-338.

4. Evans, H.E.; Knowles, G. A Model for Creep in Pure Metals. Acta Metall. 1977, 25, 963-975. [CrossRef]

5. Shi, L.; Northwood, D.O. Dislocation Network Models for Recovery Creep Deformation. J. Mater. Sci. 1993, 28, 5963-5974. [CrossRef]

6. Kassner, M.E.; Miller, A.K.; Sherby, O.D. The Separate Roles of Forest Dislocations and Subgrains in the Isotropic Hardening of Type 304 Stainless Steel. Metall. Trans. 1982, 13A, 1977-1986. [CrossRef]

7. Ardell, A.J.; Przystupa, M. Dislocation Link-length Statistics and Elevated Temperature Deformation of Crystal. Mech. Mater. 1984, 4, 319-332. [CrossRef]

8. Ginter, T.J.; Mohamed, F.A. The Stress Dependence of the Subgrain Size in Aluminum. J. Mater. Sci. 1982, 17, 2007-2012. [CrossRef]

9. Konig, G.; Blum, W. Comparision between the Cell Structures Produced in Aluminum by Cycling and by Monotonic Creep. Acta Metall. 1980, 28, 519-537. [CrossRef]

10. Kassner, M.E. Determination of Internal Stresses in Cyclically Deformed Cu Single Crystals Using CBED and Dislocation Dipole Separation Measurements. Acta Mater. 2000, 48, 4247-4254. [CrossRef]

11. Kassner, M.E.; Pérez-Prado, M.-T.; Long, M.; Vecchio, K.S. Dislocation Microstructures and Internal Stress Measurements by CBED on Creep Deformed Cu and Al. Metall. Mater. Trans. 2002, 33A, 311-318. [CrossRef]

(C) 2018 by the author. Licensee MDPI, Basel, Switzerland. This article is an open access article distributed under the terms and conditions of the Creative Commons Attribution (CC BY) license (http:/ / creativecommons.org/licenses/by/4.0/). 